\title{
Dimorfisme Seksual Dalam Karakteristik Epigenetis Upper \\ Viscerocranium Dari Sampel Tengkorak Manusia Gilimanuk (Bali)
}

\section{Rusyad Adi Suriyanto}

Keywords: identification, sex, dimorphism, skeletal, bones, prehistory, palaeoanthropology

\section{How to Cite:}

Suriyanto, R. A. (2006). Dimorfisme Seksual Dalam Karakteristik Epigenetis Upper Viscerocranium Dari Sampel Tengkorak Manusia Gilimanuk (Bali). Berkala Arkeologi, 26(2), 85-113. https://doi.org/10.30883/jba.v26i2.935

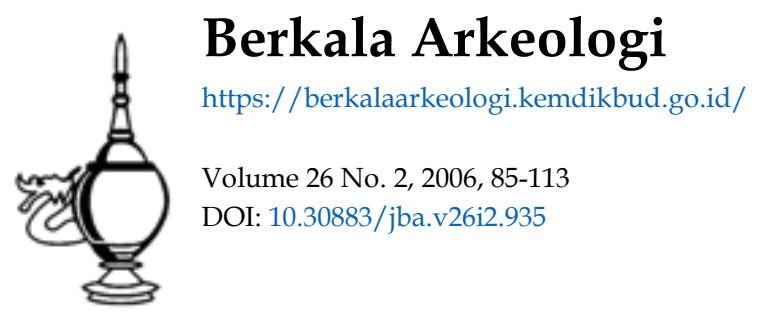

\section{cc) (7) (9)}

This work is licensed under a Creative Commons Attribution-NonCommercial-ShareAlike 4.0 International License. 


\title{
DIMORFISME SEKSUAL DALAM KARAKTERISTIK EPIGENETIS UPPER VISCEROCRANIUM DARI SAMPEL TENGKORAK MANUSIA GILIMANUK (BALI)
}

\author{
Rusyad Adi Suriyanto
}

\section{PENDAHULUAN}

Dimorfisme seksual mempelajari karakteristik-karakteristik khas padamasingmasing organisme yang berbeda seksnya, atau perbedaan derajat ekspresi yang dapat diamati di antara laki-laki dan perempuan. Perbedaan di antara dua seks ini meliputi karakteristik-karakteristik yang tidak berasosiasi langsung dengan reproduksi (Wolpoff \& Caspari, 1998). Perbedaan dimorfisme seksual spesies Homo sapiens ditunjukkan oleh ukuran, bentuk dan perilakunya (Frayer \& Wolpoff, 1985 dan Stini, 1985). Secara umum, kenyataan ini dapat terjadi pada manusia dewasa, namun belum terjadi pada bayi, anak dan remaja karena dipengaruhi hasil peristiwa-peristiwa hormonal pada masa pubertas (Beach, 1978). Secara kraniologis, perbedaan-perbedaan di antara tengkorak laki-laki dan perempuan makin berkurang seiring menuju usia tua, di mana tengkorak perempuan cenderung mendekati karakteristik-karakteristik tengkorak laki-laki(Breathnach, 1965). Dimorfisme seksual ini juga telah dipelajari dengan detail dan sangat mantap dalam sistem rangka dan gigi, karena penting untuk penentuan seks dari sisa-sisa rangka dan gigi arkeologis (Bass, 1971; Carpenter, 1976 dan Ferembach et al., 1980).

Penentuan dimorfisme seksual lebih mudah dilakukan terhadap populasi manusia hidup dibandingkan populasi arkeologisnya karena terhambat oleh jaringan lunaknya yang sudah tidak ada. Penentuan ini dalam tengkorak individu kadangkala menghadirkan keragu-raguan (Breathnach, 1965). Kepustakaan tentang dimorfisme seksual telah menghasilkan adanya dua model pendekatan, yaitu model proximate dan ultimate (Frayer \& Wolpoff, 1985). Model pertama memaparkan bahwa dimorfisme seksual merupakan jawaban terhadap tekanan nutrisi dan perbaikan 
lingkungan dalam pertumbuhan remaja. Model kedua memandang dimorfisme seksual merupakan suatu adaptasi genetis terhadap beragam faktor ekologis, sosial, ekonomis atau pembagian kerja tradisional secara seksual sebagai mekanisme pemaparan primer. Kedua model ini acapkali memegang peran kunci terhadap kesimpulan yang kabur; karena beberapa di antaranya tidak pernah cukup teruji, dan lagi pula tidak satu pun model-model ini sanggup memaparkan dengan sangat berhasil pola-pola dimorfisme seksual manusia dan primat nonhuman. Ukuran badan memang mempengaruhi dimorfisme seksual pada beberapa spesies, tetapi ini bukan suatu hubungan yang dapat dipakai secara universal. Sistem-sistem perkawinan dan pembagian kerja secara seksual dapat menyumbangkan derajat perbedaanperbedaan di antara laki-laki dan perempuan, meskipun aplikasinya terbatas. Ini dapat bermakna bahwa faktor-faktor lain dapat dipertimbangkan, karena dimorfisme seksual dihasilkan dari faktor-faktor yang tidak sama dan selalu kompleks. Bagaimanapun, model-model ini sungguh-sungguh mengakui reduksi dimorfisme seksual dalam keturunan hominid.

Dimorfisme seksual lebih jelas atau lebih besar dalam populasi-populasi yang lebih purba. Bukti-bukti kuat memang memperlihatkan reduksi dimorfisme seksual pada keturunan hominid, baik yang menyangkut dimensi-dimensi rangka, tengkorak maupun gigi (Brace \& Ryan, 1980; Wolpoff, 1980 dan Frayer \& Wolpoff, 1985). Dimorfisme seksual ukuran badan hominid telah berubah selama tiga juta tahun, dari penuh $100 \%$ seperti yang terlihat pada babun dan gorila menuju ke $20 \%$ $40 \%$ pada kelompok-kelompok manusia modern. Oleh karena itu, dimorfisme seksual ini mempunyai implikasi-implikasi penting untuk mempelajari evolusi manusia (Armelagos \& Van Gerven, 1980). Perbedaan ukuran dan bentuk ragawi pada laki-laki dan perempuan akan merefleksikan perubahan-perubahan adaptasi hominid menurut waktu. Perkecualian berasal dari bukti-bukti rangka dan gigi paleopatologis, walaupun mereka memperlihatkan adanya pola dimorfisme seksual namun derajatnya berfluktuasi dari satu populasi ke populasi yang lain, dan dari masa ke masa (Larsen, 2000).

Beberapa peneliti mempercayai bahwa reduksi dimorfisme seksual lebih ditentukan oleh evolusi manusia, yaitu dengan bertambahnya volume otak dan 
berkurangnya ukuran gigi posterior, di samping faktor-faktor kebudayaan yang bercampur dengan sumber-sumber seleksi biologis yang sebelumnya telah bekerja dalam leluhur manusia fosil. Hominid-hominid Plio/Pleistosen memperlihatkan suatu derajat dimorfisme seksual untuk dimensi-dimensi gigi, tengkorak dan rangka yang lebih besar daripada kelompok-kelompok keturunan berikutnya(Wolpoff, 1980 dan Frayer \& Wolpoff, 1985). Kelompok-kelompok Paleolitik Atas dari Eropa mempunyai dimorfisme seksual yang lebih jelas daripada keturunan-keturunan Mesolitik dan Neolitik-nya (Frayer, 1980). Kelompok-kelompok Paleolitik Atas memperlihatkan rata-rata dimorfisme seksual neurokraniumnya 4,6\%, Mesolitik 4,2 \% dan Neolitik 2,9\%; untuk viscerocraniumnya berturut-turut 8,1 \%, 5,9\% dan 5,2 \%; serta untuk mandibulanya berturut-turut 6,7 \%, 6,0\% dan 5,4\%. Sebab utama pengurangan ini adalah grasilisasi laki-laki di antara Paleolitik Atas dan Mesolitik yang dikaitkan terhadap perubahan pola-pola teknologis yang berasosiasi dengan berburu dan tipe-tipe binatang buruannya. Hal yang sama terjadi di antara Mesolitik ke Neolitik dan dari Neolitik ke populasi-populasi Eropa modem yang memperlihatkan pertalian lebih dekat dengan perubahan-perubahan yang terjadi di antara perempuan.

Dimorfisme seksual dalam ukuran gigi hominid dipengaruhi oleh adaptasi selama Pleistosen Tengah. Perkembangan teknik-teknik memproses makanan pada Pleistosen Akhir berperan penting mereduksi dimensi-dimensi gigi laki-laki dan perempuannya, dari teknik dan tipe berburu binatang-binatang besar ke binatangbinatang lebih kecil dan bertambahnya kebutuhan konsumsi tanaman (Brace \& Ryan, 1980).

Tengkorak dapat dibagi dalam neurokranium yang menutupi dan melindungi otak, dan viscerocranium yang membentuk muka. Viscerocranium merupakan suatu aparatus luar biasa yang menyusun struktur-struktur dasar sebagai tempat asupan kebutuhan utama untuk kehidupan, antara lain udara, air dan makanan, serta menyelenggarakan fungsi-fungsi pokok yang berkaitan dengan penglihatan, penciuman, pendengaran dan kemampuan bicara (Oyen, 1997). Penelitian ini hanya mencakup upper viscerocranium, yaitu viscerocranium tanpa mandibula. Pembatasan ini dituntut oleh alasan metodologis, di mana tiap-tiap individu dari 
sampel tengkorak manusia yang ditemukan di situs arkeologis Gilimanuk (Pulau Bali) belum tentu bersama dengan mandibulanya, atau sebaliknya, mandibula yang ditemukan belum tentu kepunyaan suatu individu dari sampel tengkorak tersebut, dan sebagian memang ditemukan tanpa mandibulanya.

Morfogenesis upper viscerocranium, yang merupakan bagian dari tengkorak, dikontrol oleh suatu program genetis yang sudah dimodifikasi faktor-faktor lingkungan (Schumacer, 1997). Ekspansi otak dan organ-organ indera menentukan morfogenesis dalam periode embrionis, dan perkembangan aparatus rahang merupakan faktor yang berperan dalam periode posnatal. Faktor-faktor genetis dan lingkungan saling tumpang tindih antara satu dengan lainnya selama proses ini, yang menjadikan perubahan-perubahan morfologis tidak selalu kentara. Faktorfaktor genetis intrinsik memanifestasikan karakteristik lokal, sedangkan faktorfaktor epigenetis memanifestasikan karakteristik lokal dan general, demikian halnya faktor-faktor lingkungan.

Hauser \& De Stefano (1989) menggambarkan epigenetik sebagai suatu proses determinasi dan diferensiasi progresif sel-sel dan jaringan-jaringan sebagai suatu hasil kerja perintah genetis dalam suatu progres lingkungan. Epigenetik dapat pula dikatakan sebagai suatu hubungan karakteristik gen langsung, di manakarakteristik tersebut hanya berubah oleh frekuensi gennya, yakni sebagai suatu hasil proses mutasi, dan bebas dipengaruhi perubahan lingkungan selama ontogeni. Herring (2002) melanjutkan bahwa epigenetik juga merujuk pada transformasi primordium yang sama di dalam suatu organisme yang berbeda, dan telah dipakai sebagai suatu alternatif untuk formasi awal. Epigenetik ini diterapkan untuk membedakan kemunculan bertahap dalam perkembangan kompleks embrioris pada awalnya, dan penerapannya yang merujuk konteks evolusioner berkembang di awal abad 20.

Batas-batas suatu kemampuan genetis memang tidak mudah ditentukan (Damon, 1977). Ada yang berubah cepat, namun ada pula yang lambat; tetapi semua akan berubah dalam rentang waktu tertentu (Boyd, 1962 dan Dobzhansky, 1962). Kemampuan genetis ini dapat menjelaskan bagaimana gen-gen mempengaruhi 
perkembangan anatomis-fisiologis. Gen-gen yang mempengaruhi perkembangan ini merupakan suatu tanda varian-varian epigenetis (Berry \& Berry, 1967).

Penelitian mengenai karakteristik epigenetis pernah dilakukan oleh beberapa peneliti. Dobzhansky (1962), Damon (1977) dan Hauser \& De Stefano (1989) mengemukakan bahwa perbedaan karakteristik epigenetis di dalam populasi itu sangat kecil, walaupun laki-laki dan perempuan secara genetis memang berbeda. Schwidetzky (1978) menyimpulkan perbedaan yang kecil demikian dengan ciri berkurang simpang bakunya dan berfrekuensi tinggi karakteristik epigenetisnya.

Murphy (1956) berkesimpulan bahwa pterion (regio pertemuan tulang frontal, parietal, temporal dan sphenoid pada anterolateral tengkorak) penduduk asli Australia ditentukan secara genetis, dan ini didukung oleh penelitian El-Najjar \& Dawson (1977) dan Pal et al. (1986). Kaul et al. (1979) meneliti 69 karakteristik epigenetis populasi Uttar Pradesh, Bihar, Andhra Pradesh dan Rupkund (India), dan berkesimpulan perbedaan ini dipengaruhi oleh pola-pola pemisahan geografis. Pal et al. (1988) meneliti 21 karakteristik epigenetis populasi tengkorak Gujarat (India), dan berkesimpulan populasi ini berbeda besar dari populasi tengkorak penduduk asli Australia, berbeda cukup besar dari populasi tengkorak penduduk Myanmar, Amerika Selatan dan Negrid Afrika, tetapi berbeda tipis dari populasi tengkorak penduduk Punjab, Mesir dan Kaukasus yang dipengaruhi faktor ras dan migrasi.

Strouhal \& Jungwirth (1979) mengoreksi hasil penelitian yang dilakukan para ilmuwan sebelumnya dengan menerapkan 48 karakteristik epigenetis terhadap sisasisa rangka dari situs kubur Sayala (Mesir), dan berkesimpulan populasi ini berasal dari Gurun Timur. Kebermaknaan karakteristik epigenetis terhadap sisa-sisa rangka kuno adalah dapat memperlihatkan bagaimana pewarisan gen-gen keluarga Homo sapiens, dan dapat memperkirakan pewarisan gen-gen dari sisa-sisa rangka manusia dari konteks kubur (Buikstra \& Ubelaker, 1994), serta dapat mencari jejak hubungan genetis di antara populasi kuno (Berry \& Berry, 1967 dan Berry, 1975).

Penelitian karakteristik epigenetis bermakna lebih luas dibandingkan penelitian morfometris melulu (Berry, 1979), karena mampu memberikan informasi tentang 
dinamika populasi (Coseddu et al., 1979; Kaul et al., 1979; Perizonius, 1979 dan Strouhal \& Jungwirth, 1979). Pal et al. (1988) mengatakan dengan lebih tegas bahwa kajian ini mulai memainkan peranan penting dalam analisis osteologis dewasa ini, terutama mampu untuk merekam material tulang yang fragmentaris, tidak lengkap dan kurang terpelihara dari sisa-sisa rangka paleoantropologis dan arkeologis.

Evolusi dimorfisme seksual memperlihatkan bahwa perbedaan-perbedaan karakteristik tertentu pada morfologik hominid di antara laki-laki dan perempuannya makin berkurang ke arah sekarang, atau dengan kata lain, lebihnyata dalam populasipopulasi yang lebih purba. Penelitian-penelitian ini umumnya membandingkan ukuran antropometris atau osteometris tertentu, yang biasanya dari hasil rata-rata sampel/ populasi di antara laki-laki dan perempuannya, sedangkan untuk karakteristik epigenetisnya masih terbatas. Hasil-hasil penelitian yang diperoleh tentang keberadaan dimorfisme seksual dalam karakteristik epigenetis tengkorak menunjukkan konsistensi yang kecil (Cosseddu, et al., 1977). Walaupun demikian, beberapa karakteristik ini lebih nyata pada laki-laki, di mana Hauser \& De Stefano (1989)menduga hal ini berkaitan dengan manifestasi awalnya yang berlatar belakang genetis, yaitu kemunculannya lebih awal pada laki-laki, yang selanjutnya mengalami pertumbuhan progresif sampai usia dewasa, dan kemudian terpelihara secara konstan.

Penelitian ini bertujuan untuk mengetahui dimorfisme seksual dalam karakteristik epigenetis upper viscerocranium pada sampel tengkorak manusia dari situs arkeologis Gilimanuk (Pulau Bali) yang berantikuitas 1500-2000 tahun dan berkebudayaan Logam Awal.

\section{BAHAN DAN CARA}

Subjek penelitian adalah tengkorak manusia dewasa yang berasal dari situs Gilimanuk. Sampel tengkorak ini berjumlah 20 buah, terdiri atas 13 laki-laki dan 7 perempuan. Sampel terseleksi ini didasarkan kriteria anatomis-antropologis, seleksi seks dan umur biologis oleh Krogman (1962), Brothwell (1965), Suprijo (1982, 1985), Rogers (1984), Bass (1983), White (1991), Buikstra \& Ubelaker (1994) 
dan Pickering \& Backman (1997). Seleksi kriteria karakteristik epigenetisnya didasarkan pada Berry (1975), Perizonius (1979), Hauser \& De Stefano (1989), Buikstra \& Ubelaker (1994) dan Indriati (2001).

Tengkorak-tengkorak ini berasal dari situs kubur yang teratur, dan bukan material yang ditemukan kebetulan di suatu situs secara terlepas dari hubunganjelas dengan lingkungannya. Konteks situs yang terjamin demikian memungkinkan inferensi yang lebih luas (Schiffer, 1976). Lingkungan dan praktek kebudayaan yang terungkap dapat menjadi indikator untuk membantu interpretasi biologis populasinya, khususnya yang termanifestasikan pada tulang (Swedlund \& Wade, 1972).

Karakteristik epigenetis intrapopulasi lebih umum ditemukan secara bilateral, dan hanya sebagian saja yang tunggal. Tuberculum pharyngeum, torus palatinus, sutura metopica dan os incae menupakan karakteristik tunggal; sedangkan sulcus frontalis merupakan karakteristik yang dapat bilateral atau tunggal, di manajika tunggal terdapat pada tulang frontal sisi kiri. Karakteristik epigenetis dalam penelitian ini diambil dari sampel tengkorak sisi kiri, karena secara lengkap dapat diamati dan dicatat. Beberapa sampel tengkorak sisi kanan yang mengalami fraktur parah dan hilang beberapa bagiannya meliputi R.III, R.IVA, R.VIA, R.XVIII, R.XX, R.XXVII, R.XXXVIIIB dan R.LXXXVI. Sampel Gilimanuk yang lain merupakan tengkorak yang secara umum utuh, kondisi baik dan terpelihara, kecuali R.VIIIA yang mengalami patologis pada bagian basis medioteral kirinya, berupa facies condylaris, canalis condylaris dan processus paracondyloideus yang menyatu dan berkembang ke inferolateral kiri secara berlebihan (hiperostosis). Pengamatandan pemeriksaan sampel ini yang masih utuh, lengkap dan terpelihara menunjukkan selalu ada korelasi bilateral atau manifestasi simetris karakteristik epigenetisnya. Bukti simetris ini merupakan hal yang umum, oleh karena itu membedakan sisi tidak relevan, dan syarat ini juga tidak bermakna (Berry, 1979; Cossedu et al., 1979 dan Pal et al., 1988).

Sampel tengkorak terseleksi ini lebih lanjut dilakukan pengamatan, pengukuran dan pencatatan karakteristik epigenetisnya. Karakteristik epigenetis pada upper 
viscerocraniumnya yang diteliti adalah jumlah foramen palatinum, ukuran foramen palatinum, bentuk foramen palatinum, derajat ekspresi torus palatinus, kontinuitas torus palatinus, derajat ekspresi torus maxillae, derajat ekspresi os japonicum, derajat kelengkapan tuberculum marginale, kekuatan projeksi tuberculum marginale, derajat ekspresi sutura infraorbitalis, jumlah foramen infraorbitale, derajat ekspresi foramen infraorbitale, jumlah foramen zygomaticofasiale dan ukuran foramen zygomaticofasiale (Gambar 1). Penilaian dan pengkategorian kualitatif dan kuantitatifkarakteristik ini merujuk pada Hauser \& De Stefano (1989) dan Buikstra \& Ubelaker (1994). Metode statistik nonparametrik diterapkan untuk menganalisis data nominal dan ordinal yang didasarkan penilaian dan pengkategorian tersebut. Data kualitatif yang diperoleh tersebut dijabarkan dalam bentuk nilai tertentu, yang selanjutnya dikuantifikasikan. Hasil kuantifikasi ini diuji dengan statistik nonparametrik Mann-Whitneydengan taraf signifikansi $99,95 \%$ untukmengetahui perbedaan di antara laki-laki dan perempuannya. 


\section{Pandangan frontal}

10. Derajat ekspresi sutura infraorbitalis

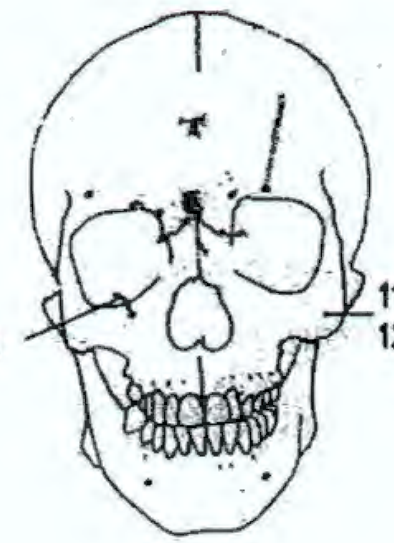

11. Jumlah foramen infraorbitale

12. Derajat ekspresi foramen infraorbitale

\section{Pandangan basal}

6. Derajat ekspresi torus maxillae

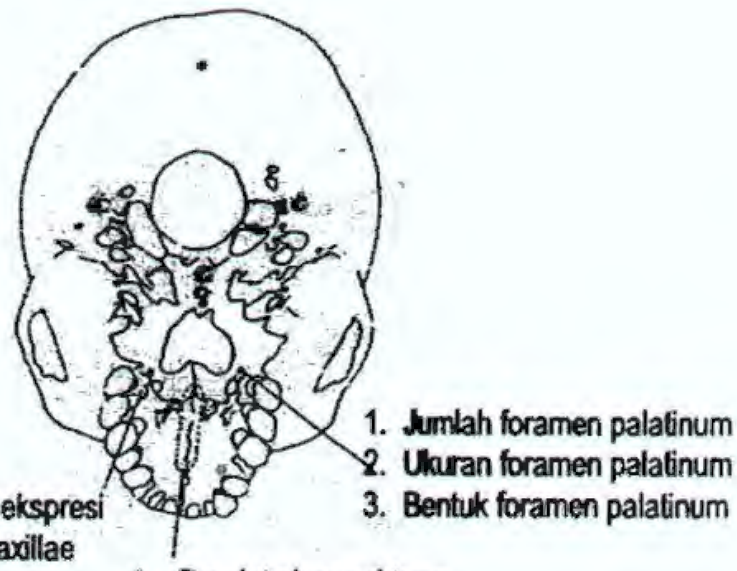

4. Derajat ekspresi torus palafinus

5. Kontinuitas torus patatinus

\section{Pandangan lateral}

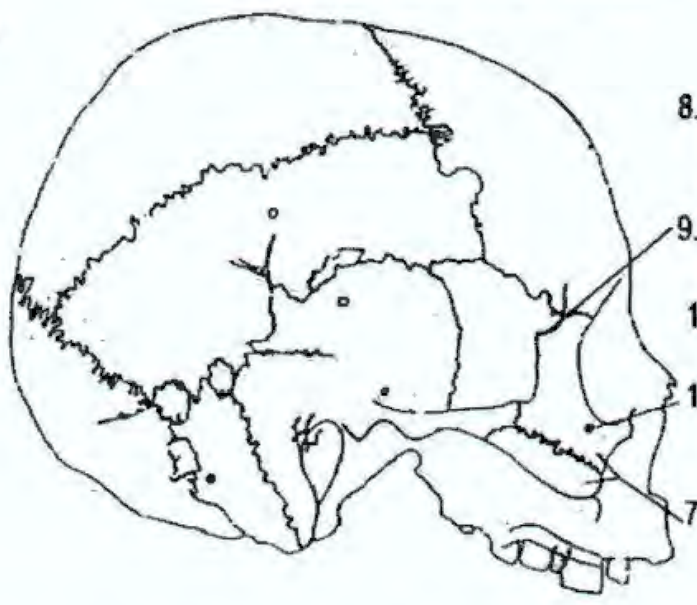

8. Derajat kelengkapan tuberculum marginale

9. Kekuatan projeksi tuberculum

13. Jumlah foramen zygomaticofaciale

14. Ukuran foramen zygomaticofaciale

7. Derajat ekspresi os japonicum

Sumber : diadopsi dan dimodifikasi dari Hauser \& De Stefano (I989)

Gambar 1. Karakteristik epigenetis upper viscerocranium yang diteliti dalam pandangan frontal. basal dan lateral 
Analisis statistik diinterpretasikan untuk menjawab pertanyaan penelitian, dan rekonstruksi dilakukan beberapa tingkat, serta kemudian ekstrapolasi sampai beberapa jenjang (Jacob, 1982, 1983). Bobot informatif, diskriminatif dan determinatif yang terdapat dalam berbagai jenis variabel dalam penelitian ini dimanfaatkan untuk mengimbangi faktor-faktor yang mengurangi keterwakilan suatu variabel. Beberapa laporan penelitian paleoantropologis, arkeologis dan geologis situs Gilimanuk dipakai untuk memperluas dan memperdalam interpretasi hasil analisis statistiknya.

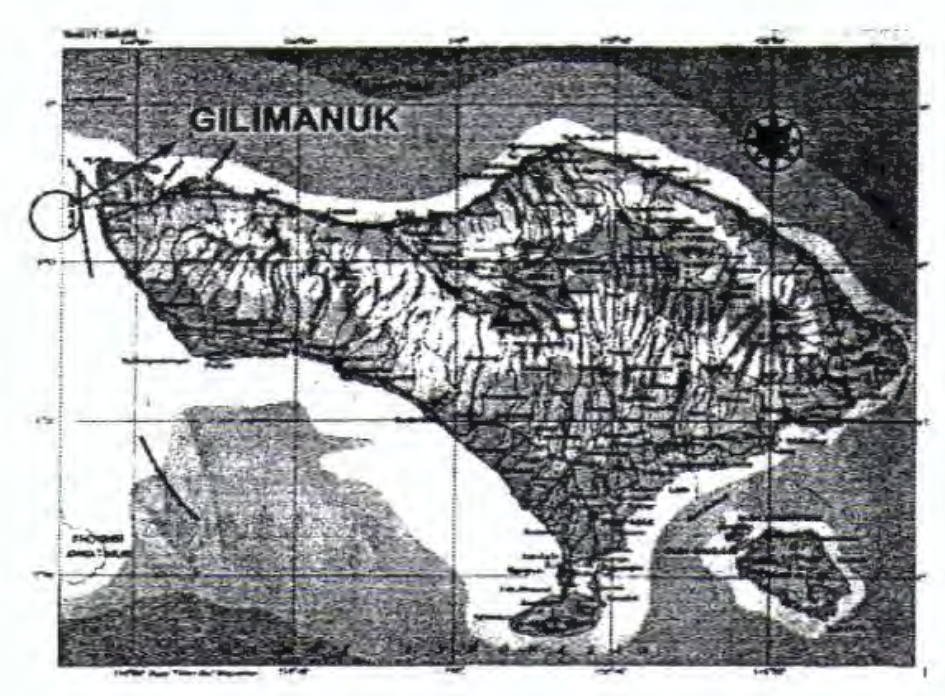

Gambar 2 A. Lokasi situs Gilimanuk

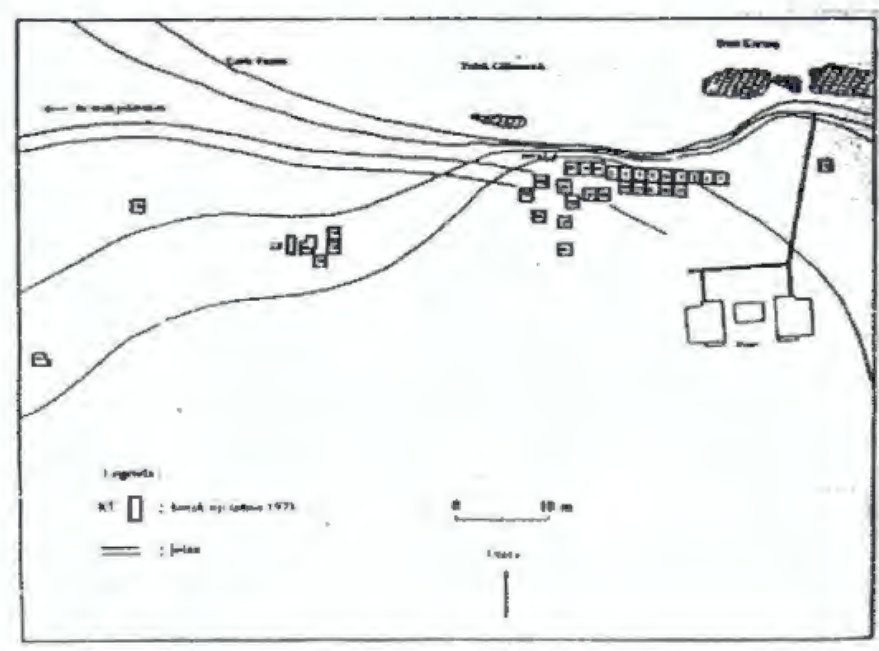

Gambar 2 B. Kotak-kotak ekskavasinya (Pusat Penelitian Arkeologi Nasional, 1990) 
Gilimanuk adalah situs kubur dan penghunian dari Zaman Paleometalik dengan antikuitas 1500-2000 tahun yang berada di pantai barat Bali, Kelurahan Gilimanuk, Kecamatan Melaya, Kabupaten Jembrana (Jacob, 1967, 1974 dan Soejono, 1995). Hasil pertanggalan $\mathrm{C}^{14}$ terhadap tulang manusianya ditemukan umur 14862466 tahun, sedangkan terhadap arangnya ditemukan umur 1805-1990 tahun (Azis et al., 1994). Letak situs berada pada bagian selatan dari Teluk Gilimanuk, dengan posisi koordinat $114^{\circ} 26^{\prime} 57^{\prime \prime}-114^{\circ} 29^{\prime} 10^{\prime \prime}$ Bujur Timur dan $8^{\circ} 9^{\prime} 3^{\prime \prime}-8^{\circ} 12^{\prime} 59^{\prime \prime}$ Lintang Selatan, serta merupakan semenanjung kecil yang diapit Teluk Prapat Agung (Azis, 1996). Situs ini juga berbentang alam satuan morfologis daratan pantai dengan stratigrafik satuan batu gamping, batupasir gampingan, endapan teras pantai I-II, dan pasir berlumpur yang meliputi luas $2 \mathrm{~km}^{2}$ (Yuliati, 1995, 1997 dan Azis, 1996). Sisa-sisa rangka manusia ditemukan pada satuan endapan aluvial teras pantai yang tersebar di sebelah timur Teluk Gilimanuk, di mana mengikuti garis pantai secara lateral dan membentuk undak-undak secara vertikal (Azis, 1995, 1996). Penelitian dari tahun 1964 sampai kini telah dibuka 37 kotak ekskavasi, dan terkumpul 123 individu rangka manusia dari usia bayi sampai dewasa; serta dengan bekal kubur berupa gerabah, manik-manik, benda logam, cangkang kerang dan binatang (Azis, 1995 dan Yuliati, 1995, 1997). Beberapa posisi penguburan ditemukan di sini; meliputi posisi terlentang tanpa wadah, posisi fleksi, dan penguburan dalam tempayan, di mana beberapa diantaranya terdiri dari dua tempayan yang disusun menangkup mulut dengan mulut (Soejono, 1977a, 1977b, 1979). Sebagian kecil temuan didapatkan dari penguburan primer tanpa wadah, sedangkan yang lain dari penguburan sekunder dalam tempayan, serta gabungan dari penguburan primer dan sekunder (Azis, 1995 dan Yuliati, 1995, 1997). Populasi Gilimanuk memperlihatkan unsur karakteristik Mongolid yang sangat kuat (Jacob, 1967, 1974 dan Suprijo, 1982, 1985).

\section{HASIL}

Perbedaan karakteristik epigenetis pada upper viscerocranium laki-laki dan perempuan dari sampel tengkorak manusia Gilimanuk terdapat pada 5 karakteristik, yaitu : ukuran foramen palatinum, derajat ekspresi torus palatinus, derajat ekspresi torus maxillae, kekuatan projeksi tuberculum marginale dan ukuran foramen zygomaticofasiale (Tabel 1). Perbedaan-perbedaan ini di antara seks diperlihatkan 
oleh indikator pertumbuhan material tulang pada laki-lakinya, atau dengan kata lain, bertumbuh dimensi-dimensi ukurannya.

Tabel 1. Frekuensi dan hasil uji perbedaan karakteristik epigenetis upper viscerocranium di antara laki-laki dan perempuan sampel tengkorak manusia Gilimanuk.

\begin{tabular}{|c|c|c|c|c|c|c|}
\hline No. & Karakteristik epigenetis & $\begin{array}{l}\mathbf{N} \\
\sigma^{a} \\
\end{array}$ & f $\sigma^{1}$ & $\begin{array}{l}\mathbf{N} \\
9 \\
\end{array}$ & $\mathbf{f} 9$ & $\mathbf{Z}$ \\
\hline \multirow[t]{5}{*}{1.} & Jumlah foramen palatinum & 13 & & 6 & & 0,000 \\
\hline & a. tidak ada & & & & & \\
\hline & b. 1 & & $\begin{array}{l}13(100,0 \\
\%)\end{array}$ & & $\begin{array}{l}6(100,0 \\
\%)\end{array}$ & \\
\hline & c. 2 & & & & & \\
\hline & d. $>3$ & & & & & \\
\hline \multirow[t]{5}{*}{2.} & Ukuran foramen palatinum & 13 & & 6 & & $3,373 *$ \\
\hline & a. dangkal $(\leqslant 0,3 \mathrm{~mm})$ & & & & & \\
\hline & b. medium $(>0,3 \mathrm{~mm}$ dan $\leqslant 1,0 \mathrm{~mm})$ & & & & $\begin{array}{l}4(66,6 \\
\%)\end{array}$ & \\
\hline & c. dalam $(>1,0 \mathrm{~mm}$ dan $\leqslant 2,0 \mathrm{~mm})$ & & $1(7,7 \%)$ & & $\begin{array}{l}1(16,7 \\
\%) \\
\end{array}$ & \\
\hline & d. sangat dalam $(>2,00 \mathrm{~mm})$ & & $\begin{array}{l}12(92,3 \\
\%)\end{array}$ & & $\begin{array}{l}1(16,7 \\
\%)\end{array}$ & \\
\hline \multirow[t]{4}{*}{3.} & Bentuk foramen palatinum & 13 & & 6 & & 0,000 \\
\hline & a. membulat & & & & & \\
\hline & b. oval & & $\begin{array}{l}13(100,0 \\
\%)\end{array}$ & & $\begin{array}{l}6(100,0 \\
\%)\end{array}$ & \\
\hline & c. celah & & & & & \\
\hline
\end{tabular}


Tabel 1. Lanjutan

\begin{tabular}{|c|c|c|c|c|c|c|}
\hline No. & Karakteristik epigenetis & $\begin{array}{l}\mathbf{N} \\
0 \\
\end{array}$ & fơ & $\begin{array}{l}\mathbf{N} \\
9 \\
\end{array}$ & f 9 & $\mathbf{z}$ \\
\hline \multirow[t]{5}{*}{4.} & Derajat ekspresi torus palatinus & 13 & & 6 & & $2,094^{*}$ \\
\hline & $\begin{array}{l}\text { a. jejak (elevasi rendah, baik parsial } \\
\text { atau lengkap) }\end{array}$ & & & & $\begin{array}{l}2(33,3 \\
\%)\end{array}$ & \\
\hline & b. medium (elevasi berkembang baik) & & & & & \\
\hline & $\begin{array}{l}\text { c. kuat (torus hampir mencakup } \\
\text { keseluruhan palatin) }\end{array}$ & & $\begin{array}{l}11(84,6 \\
\%)\end{array}$ & & $\begin{array}{l}4(66,7 \\
\%)\end{array}$ & \\
\hline & $\begin{array}{l}\text { d. sangat kuat (torus dan elevasinya } \\
\text { berkembang sangat kuat) }\end{array}$ & & $\begin{array}{l}2(15,4 \\
\%) \\
\end{array}$ & & & \\
\hline \multirow[t]{4}{*}{5.} & Kontinuitas torus palatinus & 13 & & 6 & & $-0,989$ \\
\hline & a. diskontinu & & & & & \\
\hline & b. kontinu elevasi rendah & & $\begin{array}{l}11(84,6 \\
\%) \\
\end{array}$ & & $\begin{array}{l}6(100,0 \\
\%)\end{array}$ & \\
\hline & c. kontinu elevasi tinggi & & $\begin{array}{l}2(15,4 \\
\%)\end{array}$ & & & \\
\hline \multirow[t]{3}{*}{6.} & Derajat ekspresi torus maxillae & 13 & & 7 & & $2,495^{*}$ \\
\hline & a. kecil & & & & \begin{tabular}{|l|}
$3(42,9$ \\
$\%)$ \\
\end{tabular} & \\
\hline & $\begin{array}{l}\text { b. besar (be rkembang baik ke molar } \\
\text { buccal) }\end{array}$ & & $\begin{array}{l}13(100,0 \\
\%)\end{array}$ & & $\begin{array}{l}4(57,1 \\
\%)\end{array}$ & \\
\hline \multirow[t]{3}{*}{7.} & Derajat ekspresi os japonicum & 13 & & 7 & & $-0,734$ \\
\hline & a. parsial & & $\begin{array}{l}10(76,9 \\
\%)\end{array}$ & & $\begin{array}{l}7(100,0 \\
\%)\end{array}$ & \\
\hline & b. total & & $\begin{array}{l}3(23,1 \\
\%)\end{array}$ & & & \\
\hline
\end{tabular}


Tabel 1. Lanjutan

\begin{tabular}{|c|c|c|c|c|c|c|}
\hline No. & Karakteristik epigenetis & $\begin{array}{l}\mathbf{N} \\
\sigma^{1}\end{array}$ & fơ & $\begin{array}{l}\mathbf{N} \\
+ \\
\end{array}$ & f 9 & $\mathbf{Z}$ \\
\hline \multirow[t]{3}{*}{8.} & $\begin{array}{l}\text { Derajat kelengkapan tuberculum } \\
\text { marginale }\end{array}$ & 13 & & 7 & & $-1,344$ \\
\hline & a. tidak ada & & $\begin{array}{l}10(76,9 \\
\%)\end{array}$ & & $\begin{array}{l}7(100,0 \\
\%)\end{array}$ & \\
\hline & b. ada & & $\begin{array}{l}3(23,1 \\
\%)\end{array}$ & & & \\
\hline \multirow[t]{4}{*}{9.} & $\begin{array}{l}\text { Kekuatan projeksi tuberculum } \\
\text { marginale }\end{array}$ & 13 & & 7 & & $2,883^{*}$ \\
\hline & $\begin{array}{l}\text { a. } \leqslant 4,0 \mathrm{~mm} \text {, dan depresi } \\
\text { dangkal pada basis) }\end{array}$ & & & & $\begin{array}{l}4(57,1 \\
\%)\end{array}$ & \\
\hline & $\begin{array}{l}\text { b. medium }(>4,0 \mathrm{~mm} \text { dan } \leqslant 7,0 \mathrm{~mm} \\
\text { dengan depresi baik) }\end{array}$ & & $\begin{array}{l}12(92,3 \\
\%)\end{array}$ & & $\begin{array}{l}3(42,9 \\
\%) \\
\end{array}$ & \\
\hline & $\begin{array}{l}\text { c. kuat ( }>7,0 \mathrm{~mm} \text { dengan depresi } \\
\text { sangat kuat) }\end{array}$ & & $1(7,7 \%)$ & & & \\
\hline \multirow[t]{4}{*}{10.} & Derajat ekspresi sutura infraorbitalis & 13 & & 7 & & $-1,363$ \\
\hline & a. orbital & & & & $\begin{array}{l}1(14,3 \\
\%)\end{array}$ & \\
\hline & b. facial & & & & & \\
\hline & c. total & & $\begin{array}{l}13(100,0 \\
\%)\end{array}$ & & $\begin{array}{l}6(85,7 \\
\%)\end{array}$ & \\
\hline \multirow[t]{3}{*}{11.} & Jumlah foramen infraorbitale & 13 & & 7 & & $-1,828$ \\
\hline & a. 1 & & $1(7,7 \%)$ & & $\begin{array}{l}3(42,9 \\
\%) \\
\end{array}$ & \\
\hline & b. 2 & & $\begin{array}{l}12(92,3 \\
\%)\end{array}$ & & $\begin{array}{l}4(57,1 \\
\%)\end{array}$ & \\
\hline & $3 . \geqslant 3$ & & & & & \\
\hline
\end{tabular}


Tabel 1. Lanjutan

\begin{tabular}{|c|c|c|c|c|c|c|}
\hline No. & Karakteristik epigenetis & $\mathbf{q}$ & fơ & $\begin{array}{l}\mathbf{N} \\
q \\
\end{array}$ & f 9 & $\mathbf{z}$ \\
\hline \multirow[t]{5}{*}{12.} & Derajat ekspresi foramen infraorbitale & 13 & & 7 & & $-1,340$ \\
\hline & $\begin{array}{l}\text { a. jejak (adanya lingula parsial yang } \\
\text { memisahkan foramen) }\end{array}$ & & $\begin{array}{l}10(76,9 \\
\%)\end{array}$ & & $\begin{array}{l}7(100,0 \\
\%)\end{array}$ & \\
\hline & $\begin{array}{l}\text { b. lemah (hanya ada jembatan tulang } \\
\text { kecil yang memisahkan dua } \\
\text { foramina) }\end{array}$ & & $\begin{array}{l}2(15,4 \\
\%) \\
\end{array}$ & & & \\
\hline & c. kuat (dua foramina terpisah jelas) & & & & & \\
\hline & $\begin{array}{l}\text { d. sangat kuat (ada dua kanal yang } \\
\text { terpisah) }\end{array}$ & & $1(7,7 \%)$ & & & \\
\hline \multirow[t]{5}{*}{13.} & Jumlah foramen zygomaticofasiale & 13 & & 7 & & $-0,734$ \\
\hline & a. tidak ada & & $1(7,7 \%)$ & & & \\
\hline & b. 1 & & $\begin{array}{l}12(92,3 \\
\%) \\
\end{array}$ & & $\begin{array}{l}7(100.0 \\
\%)\end{array}$ & \\
\hline & c. 2. & & & & & \\
\hline & d. $\leqslant 3$ & & & & & \\
\hline \multirow[t]{5}{*}{14.} & Ukuran foramen zygomaticofasiale & 13 & & 7 & & $2,061^{*}$ \\
\hline & a. dangkal $(<0,8 \mathrm{~mm})$ & & & & & \\
\hline & b. medium $(>0,8 \mathrm{~mm}$ dan $\leqslant 1,0 \mathrm{~mm})$ & & $1(7,7 \%)$ & & \begin{tabular}{|l|}
$3(42,9$ \\
$\%)$ \\
\end{tabular} & \\
\hline & c. dalam $(>1,0 \mathrm{~mm}$ dan $\leqslant 1,2 \mathrm{~mm})$ & & \begin{tabular}{ll|}
$(1$ & 69,2 \\
$\%)$ & \\
\end{tabular} & & \begin{tabular}{|l|}
$4(57,1$ \\
$\%)$ \\
\end{tabular} & \\
\hline & $\begin{array}{l}\text { d. sangat dalam ( }>1,2 \mathrm{~mm} \text { dan }<2,0 \\
\mathrm{~mm})\end{array}$ & & $\begin{array}{l}3(28,1 \\
\%) \\
\end{array}$ & & & \\
\hline
\end{tabular}


Ukuran kedalaman foramen palatinum memperlihatkan sampel upper viscerocranium laki-lakinya berukuran sangat dalam $(>2,0 \mathrm{~mm}) 92,3 \%$, sedangkan sebagian besar perempuannya berukuran medium $(>0,3 \mathrm{~mm}$ dan d" $1,0 \mathrm{~mm})$ $66,6 \%$, serta dalam $(>1,0 \mathrm{~mm}$ dan d" $2,0 \mathrm{~mm}$ ) dan sangat dalam masing-masing $16,7 \%$ (Tabel 1 ).

Derajat ekspresi torus palatinus memperlihatkan sampel upper viscerocranium laki-lakinya berkecenderungan kuat (torus hampir mencakup keseluruhan palatin) $84,6 \%$ dan sebagian kecil sangat kuat (torus dan elevasinya berkembang sangat kuat) $15,4 \%$; sedangkan perempuannya sebagian besar kuat $66,7 \%$ dan jejak (elevasi rendah, baik parsial atau lengkap) 33,3\% (Tabel 1). Demikian halnya dengan derajat ekpresi torus maxillae, laki-lakinya berekspresi besar (berkembang baik ke molar buccal) $100,0 \%$; sedangkan perempuannya berekspresi besar 57,1 $\%$ dan sisanya kecil 42,9\% (Tabel 1).

Kekuatan projeksi tuberculum marginale memperlihatkan sampel upper viscerocranium laki-lakinya berukuran medium $(>4,0 \mathrm{~mm}$ dan d" $7,0 \mathrm{~mm}$ dengan depresi baik) $92,3 \%$ dan sisanya kuat ( $>7,0$ mm dengan depresi sangat kuat) 7,7 $\%$; sedangkan sebagian besar perempuannya berukuran samar (d" $4,0 \mathrm{~mm}$, dan depresi dangkal pada basis) $57,1 \%$ dan sisanya medium $42,9 \%$ (Tabel 1 ).

Ukuran kedalaman foramen zygomaticifasiale memperlihatkan sampel upper viscerocranium laki-lakinya berukuran dalam $(>1,0 \mathrm{~mm}$ dan d" $1,2 \mathrm{~mm}) 69,2 \%$, serta sebagian lagi medium $(>0,8 \mathrm{~mm}$ dan d" $1,0 \mathrm{~mm}) 7,7 \%$ dan sangat dalam $(>$ $1,2 \mathrm{~mm}$ dan d" $2,0 \mathrm{~mm}$ ) $28,1 \%$; sedangkan perempuannya berukuran dalam $57,1 \%$ dan medium $42,9 \%$ (Tabel 1 ).

\section{PEMBAHASAN}

Lima karakteristik epigenetis pada upper viscerocranium dari sampel tengkorak manusia Gilimanuk yang berbeda signifikan di antara seks memperlihatkan adanya indikator pertumbuhan material tulang atau pertambahan dimensi-dimensi ukuran tulang pada laki-lakinya. Ukuran, derajat ekspresi dan kekuatan projeksi karakteristik-karakteristik ini selalu lebih nyata pada laki-lakinya (Gambar 3). 
Ukuran kedalaman foramen palatinum yang lebih nyata ini dipengaruhi secara embriologis, di mana pembentukan ini telah terlihat pada tulang prematur fetus berumur tujuh bulan; dan merupakan apertura-apertura eksternal kanal-kanal tulang kecil yang bercabang dari kanal pterygopalatum dan meneruskan saraf-saraf dan pembuluh-pembuluh darah terutama pada jaringan lunak palatum (Hauser \& De Stefano, 1989). Karakteristik ini juga lebih mudah ditemukan pada tengkoraktengkorak dewasa (Perizonius, 1979 dan Hauser \& De Stefano, 1989). Penelitianpenelitian karakteristik ini dalam perbandingan menurut seksnya hanya dilakukan terhadap jumlah dan bentuknya, dan bukan terhadap ukuran kedalamannya (Berry, 1975; Perizonius, 1970 dan Cossedu et al., 1979). Berdasarkan kedua kriteria ini, Hauser \& De Stefano (1989) menemukan bahwa populasi prasejarah Indian Amerika memperlihatkan diformisme seksual yang lebih jelas pada mereka yang berokupasi di pedalaman daripada pantai; dan mereka ini juga memperlihatkan diformisme seksual yang lebih jelas dibandingkan populasi prasejarah Ukraina.

Derajat ekspresi torus palatinus yang lebih nyata pada laki-lakinya dibandingkan perempuannya (Gambar 3) diduga karena rata-rata umurnya lebih tua, walaupun keseluruhan sampel diindikasikan dewasa. Torus palatinus ini ditentukan oleh kekuatan merespon gangguan yang berperan penting terhadap formasinya. Formasi ini merupakan suatu jembatan tulang median yang mungkin merupakan hasil dari pemindahan sel-sel dengan pertumbuhan potensial dari posisi intrasutural ke batas inferior suturanya yang masih terdapat proses pertumbuhan. Ukuran torus palatinus ini selalu bertambah dari mulai tahap fetus akhir sampai dewasa (Hauser \& De Stefano); dan peristiwa ini lebih nyata diamati mulai umur dewasa muda, namun berangsur-angsur lemah dalam umur tua (Perizonius, 1979 dan Axelsson \& Hedegaard, 1985).

Dimorfisme seksual dalam derajat ekspresi torus palatinus memperlihatkan lebih nyata pada populasi prasejarah Ukraina daripada Indian Amerika, namun keduanya kurang nyata daripada Australia (Hauser \& De Stefano, 1989). Populasi resen Inggris dan Belanda memperlihatkan kurang nyata dibandingkan Negrid Afrika Selatan (Berry, 1975; Perizonius, 1979 dan Hauser \& De Stefano, 1989). Populasi modern Eropa (Italia dan Islandia) memperlihatkan kurang nyata dibandingkan 
Kaukasid Amerika, namun keduanya kurang nyata dibandingkan Asia Timur(Jepang dan Mongolia) (Cosseddu et al., 1979; Axelsson \& Hedegaard, 1985 dan Hauser \& De Stefano, 1989). Secara umum, keseluruhan populasi-populasi ini memperlihatkan penurunan derajat dimorfisme seksual karakteristik epigenetis ini seiring perjalanan waktu ke masa kini.
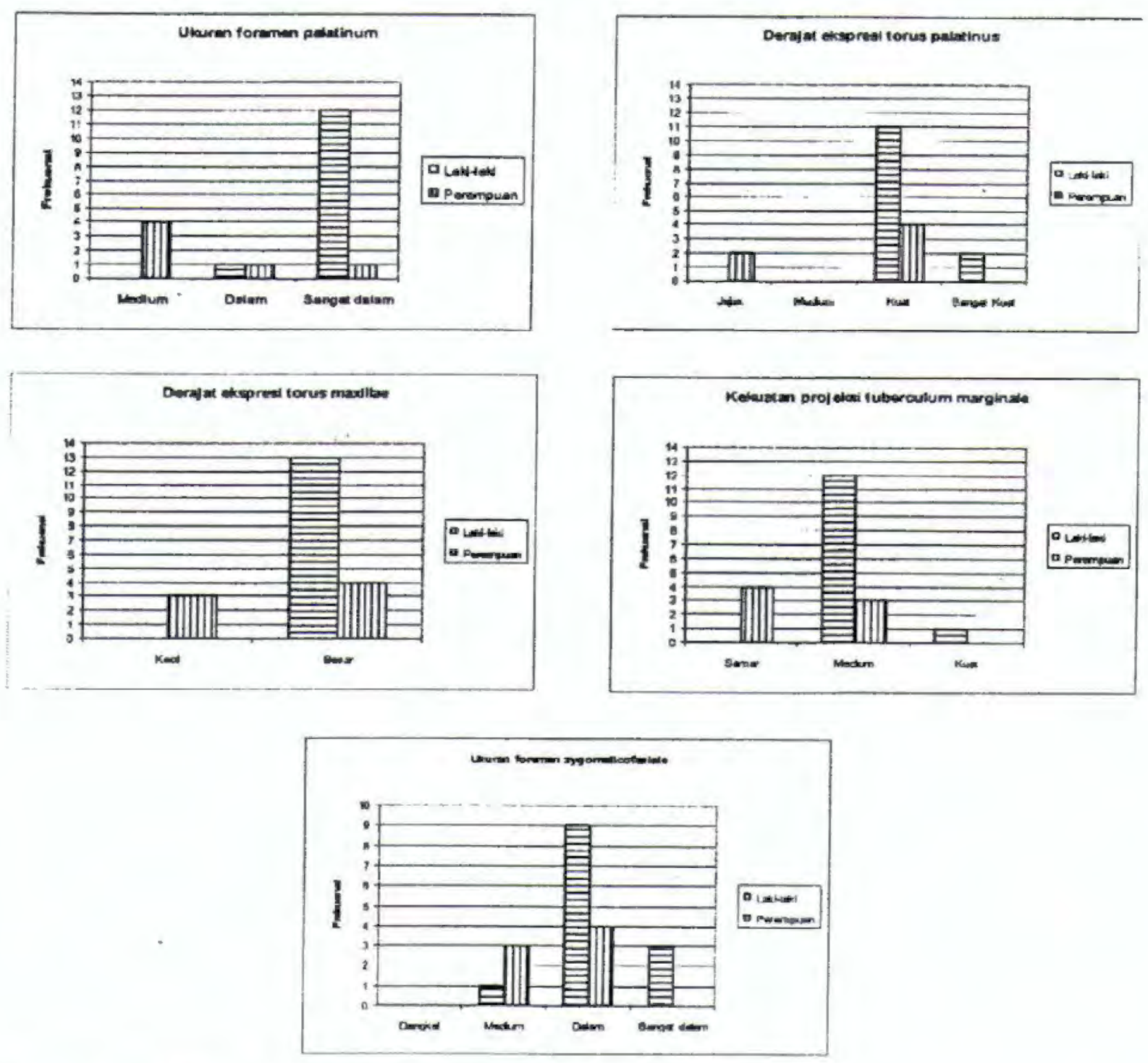

Keterangan : $:$ : Laki-laki, 而= Perempuan

Gambar 3. Frekuensi karakteristik epigenetis upper viscerocranium dari sampel tengkorak manusia Gilimanuk yang berbeda signifikan di antara seks. 
Derajat ekspresi torus maxillae lebih nyata pada laki-lakinya dibandingkan perempuannya (Gambar 3), walaupun beberapa peneliti berpendapat tidak ada perbedaan di antara seks (Corruccini, 1974 dan Milne et al., 1983), dan bahkan ada peneliti yang berpendapat lebih nyata pada perempuan (Berry, 1975). Perbedaan hasil ĩni mungkin dipengaruhi oleh penentuan umur secara kualitatifbiologis, misalnya ada peneliti yang memasukkan kelompok umur dewasa muda ke dalam kelompok remaja akhir di satu sisi, dan ada peneliti yang memasukkan sebaliknya di sisi lain. Beberapa peneliti bisa jadi memasukkan kelompok umur tua sebagai keseluruhan kelompok umur dewasa, padahal karakteristik epigenetis ini berkaitan erat dengan perkembangan torus palatinus (Hauser \& De Stefano, 1989). Jadi, karakteristik ini dapat ditemukan dalam frekuensi tinggi secara signifikan pada kelompok umur dewasa akhir. Berdasarkan rasial, dimorfisme seksual karakteristik ini lebih nyata pada populasi resen Kaukasid Eropa daripada Negrid Afrika, dan demikian pula pada populasi modern Kaukasid dengan Negrid Amerika (Hauser \& De Stefano, 1989).

Kekuatan projeksi tuberculum marginale memperlihatkan lebih nyata pada lakilakinya dibandingkan perempuannya (Gambar 3), seperti dalam kajian Perizonius (1979); namun beberapa peneliti berpendapat tidak ada perbedaan di antara seks (Hauser \& De Stefano, 1989). Penelitian mengenai karakteristik ini belum banyak dilakukan, sehingga informasi tentang genetik, embriologik, perkembangan, fungsi dan variasi intra-interpopulasinya juga sangat terbatas (Hauser \& De Stefano); namun Perizonius (1979) memberikan informasi dari sampel modern Belanda (Eropa), bahwa peristiwa kranial karakteristik ini dapat terjadi pada 47,6\% lakilakinya dan $44,8 \%$ perempuannya, serta berdasarkan sisinya pada $36,7 \%$ lakilakinya dan $30,0 \%$ perempuannya.

Ukuran kedalaman foramen zygomaticofasiale lebih nyata pada laki-lakinya dibandingkan perempuannya (Gambar 3) yang dipengaruhi oleh adanya ukuran yang sangat dalam. Ukuran ini mencakup hampir seperempat sampel laki-lakinya, tetapi tidak ditemukan pada sampel perempuannya. Penelitian tentang dimorfisme seksual dari karakteristik epigenetis ini hanya mengamati keberadaan foramennya (Berry \& Berry, 1967; Berry, 1975; Cosseddu et al., 1979; Perizonius, 1979 dan 
Hauser \& De Stefano, 1989), sedangkan ukuran kedalaman belum pernah dilakukan. Perizonius (1979) melaporkan suatu kecendenungan berfrekuensi lebih tinggi pada laki-lakinya, dan Berry \& Berry (1967), Berry (1975) dan Cosseddu et al., (1979) melaporkan tidak ada perbedaan di antara seks.

Variasi keberadaan foramen zygomaticofasiale berdasarkan kelompok umur adalah heterogen (Hauser \& De Stefano, 1989). Berry (1975) melaporkan tidak ada perbedaan signifikan dalam kelompok umur, namun Perizonius (1979) menemukan pertambahan frekuensi yang signifikan pada kelompok umur lebih tua. Foramen ini berperan sebagai jalan ekstemal pembuluh darah dan saraf untuk regio zygomaticofasiale. Kanal-kanal pembuluh darah dan saraf ini berkembang sekitar bulan ketiga embrional pada batas antara aposisi tulang orbita dan bagian tulang zygomatikum yang bertumbuh.

Penelitian tentang dimorfisme seksual karakteristik epigenetis yang berkaitan dengan keberadaan foramen zygomaticofasiale berdasarkan ras dan antikuitas pernah dilakukan oleh beberapa peneliti. Populasi prasejarah Indian Amerika (Arizona Barat Daya) memperlihatkan lebih nyata daripada populasi Siberia yang berkebudayaan Tagar (Hauser \& De Stefano, 1989). Populasi resen Belanda memperlihatkan lebih kecil daripada Inggris (Berry, 1975 dan Perizonius, 1979). Populasi modem Mongolid (Jepang) memperlihatkan lebih nyata daripada Kaukasid Amerika (Hauser \& De Stefano, 1989).

Karakteristik-karakteristik epigenetis pada upper viscerocranium dari sampel tengkorak manusia Gilimanuk yang berbeda signifikan secara seksual memperlihatkan semua lebih nyata pada laki-lakinya. Secara umum, perbedaan ini tidak begitu menyolok karena hanya meliputi variasi di dalam populasi (Hauser \& De Stefano, 1989), di mana beberapa karakteristik ini lebih nyata eksistensinya pada salah satu seks (Boyd, 1962; Dobzansky, 1962 dan Damon, 1977). Derajat dimorfisme seksual yang kecil ini didukung oleh kenyataan-kenyataan, bahwa sampel ini berantikuitas 1500-2000 tahun yang lalu, dan berkarakteristik Mongolid sangat kuat (Jacob, 1967, 1974; Suprijo, 1982, 1985 dan Soejono, 1995). Mereka juga berkebudayaan Neolitik Akhir dengan ciri utama artefak arkeologis gerabah/ 
tembikar, manik-manik dan logam (Soejono, 1977a, 1977b, 1979; Azis, 1995 dan Yuliati, 1955, 1997). Beberapa peneliti menggambarkan reduksi derajat dimorfisme seksual ini berkaitan dengan evolusi biologis dan evolusi kebudayaan (Bass, 1971; Carpenter, 1976, Beach, 1978; Armelagos \& Van Garven, 1980; Ferembach, et al., 1980; Frayer, 1980; Wolpoff, 1980; Frayer \& Wolpoff, 1985 dan Stini, 1985). Mulai hominid-hominid Plio/Pleistosen terjadi reduksi ini, baik dimensi-dimensi gigi, tengkorak dan rangka, dan terus berlanjut sampai Holosen; juga mulai dari Paleolitik Awal sampai Neolitik, dan bisa jadi berlanjut sampai kini. Jadi, pola evolusi ini mengindikasikan makin besarnya persamaan morfologik manusia laki-laki dan perempuan.

Berdasarkan artefak-artefak dan konteks arkeologisnya, maka mereka dapat direkonstruksikan sebagai populasi yang memang berokupasi dan bermatapencaharian di sekitar Teluk Gilimanuk (Soejono, 1977a, 1977b, 1979; Azis, 1995; Yuliati, 1995, 1997 dan Azis, 1996). Faktor-faktor fungsional ini jelas mempengaruhi biologis populasinya, yang dapat diindikasikan dari karakteristik tulang-tulang yang ditinggalkan (Swedlund \& Wade, 1972; Wolpoff, 1980 dan Sperber, 1989). Hauser \& De Stefano (1989) melaporkan bahwa populasi prasejarah Indian Amerika memperlihatkan dimorfisme seksual foramen palatinum yang lebih jelas pada mereka yang berokupasi di pedalaman daripada di pantai. Pembagian kerja secara seksual yang berpengaruh terhadap dimorfisme seksual berdasarkan kajian etnografis pada masyarakat-masyarakat tradisional di hampir seluruh dunia juga memperlihatkan bahwa karakteristik morfologis laki-lakinya lebih jelas dibandingkan perempuannya (Frayer, 1980). Aktivitas-aktivitas subsistensi di pedalaman lebih utama dikerjakan para laki-lakinya dibandingkan perempuannya, misalnya berburu binatang-binatang besar, berternak unggas, menjebak binatang, menjagal binatang, dan membersihkan, mempersiapkan dan mengolah lahan.

\section{PENUTUP}

Karakteristik epigenetis upper viscerocranium dari sampel tengkorak manusia Gilimanuk menunjukkan perbedaan yang signifikan $(\mathrm{p}<0,05)$ di antara laki-laki dan perempuannya pada 5 karakteristik dari 14 karakteristik yang diteliti. 
Perbedaan-perbedaan ini meliputi ukuran (kedalaman) foramen palatinum, derajat ekspresi torus palatinus, derajat ekspresi torus maxillae, kekuatan projeksi tuberculum marginale dan ukuran (kedalaman) foramen zygomaticofasiale. Ukuran, derajat ekspresi dan kekuatan projeksi karakteristik-karakteristik ini selalu lebih nyata pada laki-lakinya, yang termanifestasikan dari indikator pertumbuhan material atau pertambahan dimensi-dimensi ukuran tulangnya.

Derajat dimorfisme seksual karakteristik epigenetis dalam upper viscerocranium ini menunjukkan relatifkecil, karena bagaimanapun merupakan suatu variasi biologis di dalam populasi. Sampel yang diteliti ini berasal dari populasi Mongolid yang berokupasi dan bermatapencaharian di sekitar Teluk Gilimanuk (Pulau Bali), yang berkebudayaan Neolitik Akhir/Paleometalik dengan artefak arkeologis utama berupa gerabah/tembikar, manik-manik dan logam, serta berantikuitas sekitar 1500-2000 tahun yang lalu.

Pertambahan umur merupakan hal yang harus diperhatikan dalam penelitian dimorfisme seksual karakteristik epigenetis pada upper viscerocranium. Konsistensi penentuan umur biologis harus disepakati, karena berdasarkan pertumbuhan dan perkembangan morfologis yang bersifat kualitatif. Perbedaan interpretasi atas suatu batas kelompok umur dapat mempengaruhi hasil penelitiannya. Beberapa karakteristik epigenetis ini dapat memperlihatkan sebagian besar karakteristiknya secara optimal dan mantap pada kelompok umur dewasa, namun ada beberapa karakteristiknya yang mengalami reduksi pada umur tua. Boleh jadi, ada beberapa peneliti yang memasukkan kelompok umur dewasa muda ke dalam kelompok umur remaja akhir di satu sisi, namun ada beberapa peneliti yang memasukkan sebaliknya di sisi lain; atau ada beberapa peneliti yang memasukkan kelompok umur tua sebagai keseluruhan kelompok umur dewasa.

Relevansi praktis penelitian ini adalah memudahkan kita untuk mampu mengenali atau membedakan upper viscerocranium laki-laki dan perempuan dengan metode kualitatif, khususnya dari sisa-sisa manusia paleoantropologis dan arkeologis yang lebih sering ditemukan dalam keadaan fraktur, rapuh dan kurang terpelihara. 
Penelitian terhadap sampel tengkorak Gilimanuk menunjukkan bahwa karakteristik epigenetis ukuran (kedalaman) foramen palatinum, derajat ekspresi torus palatinus, derajat ekspresi torus maxillae, kekuatan projeksi tuberculum marginale dan ukuran (kedalaman) foramen zygomaticofasiale dapat membantu penentuan seks individunya, dengan tanpa mengabaikan faktor ras, perubahan umur dan lingkungannya.

\section{UCAPAN TERIMA KASIH}

Penulis menyampaikan terima kasih kepada Prof. DR. T. Jacob, M.S., M.D., D.Sc., yang telah mengizinkan untuk meneliti koleksi tengkorak manusia Gilimanuk yang tersimpan di Laboratorium Bioantropologi dan Paleoantropologi, Bagian Anatomi, Embriologi dan Antropologi, Fakultas Kedokteran Universitas Gadjah Mada.

\section{DAFTAR PUSTAKA}

Armelagos, GJ. \& Van Gerven, D.P. 1980 "Sexual dimorphism and human evolution : an overview". Journal of Human Evolution 9: 437-446.

Axelsson, G \& Hedegaard, B. 1985 "Torus palatinus in Iceland school children". American Journal of Physical Anthropology 67 : 105-112.

Aziz, F. A. (1995). Situs Gilimanuk (Bali) Sebagai Pilihan Lokasi Pengubudran Pada Aural Masehi. Bedrkala Adrkeologi, 15(3), 43-46. https ://doi.odrg/10.30883/jba.v15i3.669

1996 "Morfokronologi situs Gilimanuk dan sekitamya", dalam Sumijati, A. (ed.): Jejak-jejak Budaya II, pp. 105-134. Asosiasi Prehistorisi Indonesia, Yogyakarta.

Azis, F.A., Faizal, W., dan Lahagu, F. 1994 “Pertanggalan radiokarbon rangka manusia situs Gilimanuk, Bali". Proc. Ev. Hasil Penel. Arkeol. Pusat Penelitian Arkeologi Nasional, Jakarta. 
Bass, W.M. 1989 Human Osteology : A Laboratory and Field Manual, $3^{\text {rd }}$ ed. Missouri Archaeological Society Inc., Columbia.

Beach, F.A. 1978 "Human sexuality and evolution”, dalam S.L. Washburn \& E.R. Mc Cown (eds.): Human Evolution : Biosocial Perspective, pp. 123-153. Cummings, Menlo Park.

Berry, A.C., 1975 "Factors affecting the incidence of non-metrical skeletal variants".J. Anatomy $120: 519-535$.

Berry, A.C., \& Berry, R.J. 1967 "Epigenetic variation in the human cranium”. J. Anatomy 101: 361379.

Berry, R.J. 1979 "Genes and skeletons, ancient and modern”. Journal of Human Evolution 8(7) : 669-677

Boyd, W.C. 1962 "The contribution of genetics to anthropology", dalam Sol Tax (ed.): Anthropology Today, pp. 65-83. The University of Chicago Press, Chicago.

Brace, C.L. \& Ryan, A.S. 1980 "Sexual dimorphism and human tooth size differences". Journal of Human Evolution 9 : 417-435.

Breathnach, A.S. 1965 Frazer's Anatomy of Human Skeleton, $6^{\text {th }}$ ed. J. \& A. Curchill Ltd, London.

Brothwell, D.R. 1965 Digging up Bones : The Excavation, Treatment and Study of Human Skeletal Remains. British Museum of Natural History, London.

Buikstra, J.E. \& Ubelaker, D.H. (eds). 1994 Standards for Data Collection from Human Skeletal Remains. Proceedings of a Seminar at the Field Museum of Natural History, Organized by Jonathan Haas. Ar 
kansas Archeological Research Series No.44. Arkansas Archaeological Survey, Fayetteville.

Carpenter, J.C. 1976 "A comparative study of metric and nonmetric traits in a series of modern crania". American Journal of Physical Anthropology 45 : 337-344.

Corruccini, R.S. 1974 "An eximination of the meaning of cranial discrete traits for human skeletal biological studies". American Journal of Physical Anthropology 40 : 425-446.

Cosseddu, G.G., Floris, G, \& Vona, G. 1979 "Sex and side differences in the minor non-metrical cranial variants". Journal of Human Evolution 8(7) : 685-692.

Damon, A. 1977 Human Biology and Ecology. W.W. Norton \& Co., New York.

Dobzhansky, T. 1962 Mankind Evolving : The Evolution of the Human Species. Yale University Press, New Haven.

El-Najjar, M.Y., \& Dawson, G.L. 1977 "The effect of artificial deformation on the incidence of wormian bones in the lambdoidal suture'. American Journal of Physical Anthropology 46 : 155-160.

Ferembach, D., Schwidetzky, I. \& Stloukal, M. 1980 "Recommendations for age and sex diagnoses of skeleton". Journal of Human Evolution 3 : 517-549.

Frayer, D.W. 1980 "Sexual dimorphism and cultural evolution in the Late Pleistocene and Holocene of Europe". Journal of Human Evolution 9 : 399-415. 
Frayer, D.W. \& Wolpoff, M.H. 1985 "Sexual dimorphism". Ann. Rev. Anthropol. 14 : 429-473.

Hauser, G \& De Stefano, GF. 1989 Epigenetic Variants of the Human Skull. E. Schweizerbart'sche Verlagsbuch handlung, Stuttgart.

Herring, S.W. 2002 "Epigenetic and functional influences on skull growth", dalam J. Hanken \& B.K. Hall (eds.): The Skull: Development, Vol 5., pp.153-206. The University of Chicago Press, Chicago.

Indriati, E. 2001 "Bioarkeologi : integrasi dinamis antara antropologi biologis dan arkeologi". Humaniora XIII (3) : 284-291.

Jacob, T. 1967 Some Problems Pertaining to the Racial History of the Indonesian Region. Drukkerij Neerlandia, Utrecht.

1974 "Studies on human variation in Indonesia". Journal of the National Medical Association 66(5) : 389-399

1982 "Prospek penelitian paleoantropologi di Indonesia". B. Bioanthrop. Indon. III(1) : 4755

Jacob, T. 1983 "Garis-garis besar methodologi penelitian dan analisis paleoanthropologi”'. B. Bioanthro. Indon. III(3) : 145-153.

Kaul, S., Anand, V. \& Corruccini, R.S. 1979 "Non-metric variation of the skull in samples of four Indian population". Journal of Human Evolution 8(7) : 693-697.

Krogman, W.M. 1962 The Human Skeleton in Forensic Medicine. Charles C Thomas Publisher, Springfield, Ill.

Larsen, C.S. 2000 Bioarcheology : Interpreting Behavior from the Human 
Skeleton. Cambridge University Press, Cambridge.

Milne, N., Schmitt, L.H \& Freedman, L. 1983 "Discrete trait variation in Western Australian Aboriginal skulls". Journal of Human Evolution 12 : 157-168.

Murphy, A. 1956 "The pterion in the Australian Aborigines". American Journal of Physical Anthropology $14: 225-244$.

Oyen, O.J. 1997 "Evolution of form in the craniofacial complex" dalam A.D. Dixon, D.A.N. Hoyte \& O. Rönning (eds.), Fundamentals of Craniofacial Growth, p.p. 23-44. CRC Press, New York.

Pal, GP., Routal, R.V. \& Bhagwat, S.S. 1986 "A study of sutural bones in Gujarati (Indian) crania". Anthrop. Anz. $44:$ 67-76.

1988 "A study of non-metric (qualitative) variation in Gujarat crania". Anthrop. Anz, 46(1) : 65-74.

Perizonius, W.R.K. 1979 "Non-metric cranial traits: sex difference and age dependence". Journal of Human Evolution 8(7) : 679-684.

Pickering, R.B., \& Bachman, O.C. 1997 The Use of Forensic Anthropology. CRC Press, Boca Raton.

Pusat Penelitian Arkeologi Nasional 1990 Laporan Penelitian Arkeologi Situs Gilimanuk, Bali, Tahap IX. Pusat Penelitian Arkeologi Nasional, Jakarta. Tidak dipublikasikan.

Rogers, S.L. 1984 Human Skull. Charles C Thomas Publisher, Springfield, Ill. Schiffer, M. B. 1976 Behavioral Archaeology. Academic Press, New York. 
Schumacer, GH. 1997 "Principles of skeletal growth", dalam A.D. Dixon, D.A.N. Hoyte \& O. Rönning (eds.): Fundamentals of Craniofacial Growth, p.p. 1 22. CRC Press, New York.

Schwidetzky, I. 1978 "Approaches to the study of isolates in prehistoric population". Homo 29: 41-44.

1979 "Paleo-population genetics". Journal of Human Evolution 8(7): 661-667.

Soejono, R.P. 1977a Sarkofagus Bali dan Nekropolis Gilimanuk. Pusat Penelitian Purbakala dan Peninggalan Nasional, Jakarta.

1977b Sistim-sistim Penguburan pada Akhir Masa Prasejarah di Bali. Disertasi. Universitas Indonesia, Jakarta.

Soejono, R.P. 1979 The significanee of excavation at Gilimanuk (Bali), dalam R.B. Smith \& W. Watson (eds.): Early South East Asia, pp. 185198. Oxford University Press, New York.

1995 "A late prehistoric burial system in Indonesia: additional notes on Gilimanuk, Bali", dalam Conference Papers on Archaeology in South East Asia, pp.181-189. The University Museum and Art Gallery the University of Hongkong, Hongkong.

Sperber, GH. 1989 Craniofacial Embriology, $4^{\text {th }}$ ed. Butterworths, Edmonton.

Stini, W.A. 1985 "Growth rates and sexual dimorphism in evolutionary perspective", dalam R.I. Gilbert \& J.H. Milke (eds.) : The Analysis of Prehistoric Diets, pp. 191-226. Academic Press, Orlando.

Strouhal, G \& Jungwirth, J. 1979 "Paleogenetics of the late Roman-Early Byzantine cemeteries at Sayala, Egyptian Nubia". Journal of Human 
Evolution 8(7) : 699-703.

Suprijo, A. 1982 "Penelitian terhadap rangka Gilimanuk tahun 1977". REHPAI. Pusat Penelitian Arkeologi Nasional, Jakarta.

1985 "Penelitian terhadap rangka Gilimanuk tahun 1979". $\boldsymbol{R E H P A}$ II. Pusat Penelitian Arkeologi Nasional, Jakarta.

Swedlund, A.C. \& Wade, W.D. 1972 Laboratory Methods in Physical Anthropology. Prescott College Press, Prescott.

White, T.D. 1991 Human Osteology. Academic Press Inc., London.

Wolpoff, M.H. 1980 Paleoanthropology. Alfred AKnopf, New York.

Wolpoff, M.H. \& Caspari, R. 1998 Race and Human Evolution: A Fatal Attraction. Westview Press, Boulder.

Yuliati, C. 1995 Laporan Ekskavasi Situs Gilimanuk Kecamatan Melaya Kabupaten Jembrana Propinsi Bali. Balai Arkeologi Denpasar, Denpasar. Tidak dipublikasikan

1997 Laporan Penelitian Arkeologi, Ekskavasi Situs Gilimanuk Kecamatan Melaya Kabupaten Jembrana. Balai Arkeologi Denpasar, Denpasar. Tidak dipublikasikan 